\title{
Influence of Heat Treatment on Structure and Durometric Properties of Coatings Obtained by Surfacing with CSR- 04CR27NI7MO3CU2T Cast Rods
}

\author{
Aleksandr Nazarko ${ }^{1, a^{*}}$ and Roman Plomodyalo ${ }^{1, b}$ \\ ${ }^{1}$ Kuban State Technological University, 2, Moskovskaya Str., Krasnodar, 350072, Russia \\ anazarkoaleksandr@rambler.ru, bsutk_kubstu@mail.ru
}

Keywords: Argon Arc Surfacing, Cast Rod, Heat Treatment, Hardness, Structure

\begin{abstract}
The effect of heat treatment modes on the structure and durometric properties of coatings obtained by surfacing with CSR-04CR27NI7MO3CU2T cast rods, is considered. It is found that the temperature of $800^{\circ} \mathrm{C}$ and soaking time of 5 hours are optimal to increase the deposited metal hardness. It is shown that such a phenomenon results from the formation of the austenitic structure hardened by the precipitates of the $\sigma$-phase $(\mathrm{FeCr})$, chromium carbides $\left(\mathrm{Cr}_{3} \mathrm{C}_{2}\right)$ and titanium carbides (TiC). The heat treatment modes proposed can be applied in the wearresistant surfacing technology of chemical equipment parts.
\end{abstract}

\section{Introduction}

Parts of chemical equipment operating under conditions of carbamide fusion $\left(\mathrm{H}_{2} \mathrm{NCONH}_{2}\right)$ with pressure indicators of up to $20 \mathrm{MPa}$ and temperature indicators of $200^{\circ} \mathrm{C}$, gaseous and liquid ammonia, ammonium nitrate are subject to intense wear, as well as intergranular and general corrosion.

To surface the parts of carbamate pumps, throttle and shut-off elements (saddles, valves), the following procedures are most often used - manual arc surfacing with $O K 61.25$ electrodes, manual and automatic submerged-arc surfacing with the following fluxing agents - OK Autrod $316 \mathrm{LS}$ i wire [1]. Such surfacing materials ensure the production of coatings of the austenitic and ferritic class with increased wear resistance in a corrosive environment.

At the same time, the hardness of the coatings deposited with such materials is insufficient to ensure the required wear resistance. To increase the hardness of such a deposited metal, it is necessary to heat it. It should be taken into account that the modes of such heat treatment have been studied insufficiently.

Based on the above mentioned, the aim of this paper is to study the effect of heat treatment modes on the structure and durometric properties of coatings obtained by surfacing with cast rods.

\section{Research Methods}

The surfacing was carried out on the AISI $316 \mathrm{~L}$ steel plates with the dimensions of $40 \times 15 \times 10 \mathrm{~mm}$ with experimental CSR-04CR27NI7MO3CU2T cast rods [2] with their diameter of $5 \mathrm{~mm}$ and length of $270 \mathrm{~mm}$, in the argon atmosphere, in four layers, with the strength of current equal to $180 \mathrm{~A}$.

The research of the deposited metal microstructure was carried out with the help of the ZEISS EVO HD 15 MA scanning electron microscope. The microstructure was revealed by the pickling with the aqua regia reagent - a mixture of concentrated nitric acid $\mathrm{HNO}_{3}(65-68$ wt. \%) and hydrochloric acid $\mathrm{HCl}(32-35$ wt. \%) taken in a ratio of $1: 3$ by volume (with the mass ratio about $1: 2$ in terms of pure substances). 
The hardness and microhardness were measured on metal samples after surfacing and heat treatment using the $T K-2 M$ hardness tester in accordance with the method of Rockwell and the DuraScan-80 microhardness tester in accordance with the method of Vickers. Microhardness was measured along the cross section of the deposited coating, starting from the base metal with a step of $0.2 \mathrm{~mm}$ [3].

The deposited samples heat treatment was carried out in the $\Pi M-12 M 2 \Pi-1200$ muffle furnace in the modes established experimentally.

\section{Research Results and Discussion}

After surfacing, the coating hardness was researched in accordance with the method of Rockwell, and it made 29-32 HRC. However, in order to ensure high wear resistance, it is necessary to increase the hardness of the deposited metal. For this purpose, after surfacing, the samples under study were subjected to heat treatment.

Three modes of heat treatment were researched - at heating temperatures of $800^{\circ} \mathrm{C}, 900^{\circ} \mathrm{C}$ and $1,000^{\circ} \mathrm{C}$, with the soaking time from 1 hour to 6 hours. The results of measuring the hardness over the cross-section of the deposited metal are given in Table 1.

Table 1. Hardness Distribution in Coating Obtained by Surfacing with Cast Rods after Heat Treatment

\begin{tabular}{|c|c|c|c|c|c|c|}
\hline \multirow{2}{*}{$\begin{array}{c}\text { Heat } \\
\text { treatment } \\
\text { temperature, } \\
{\left[{ }^{\circ} \mathrm{C}\right]}\end{array}$} & \multirow{2}{*}{$\begin{array}{l}\text { Soaking } \\
\text { time, } \\
\text { [hours] }\end{array}$} & \multicolumn{5}{|c|}{$\begin{array}{l}\text { Hardness distribution in accordance with deposited metal } \\
\text { layers, [HRC] }\end{array}$} \\
\hline & & 1 & 2 & 3 & 4 & $\begin{array}{c}\text { Average } \\
\text { value }\end{array}$ \\
\hline \multirow{6}{*}{800} & 1 & 32 & 40 & 36 & 35 & 35.75 \\
\hline & 2 & 36 & 41 & 42 & 43 & 40.5 \\
\hline & 3 & 38 & 42 & 43 & 43 & 41.5 \\
\hline & 4 & 41 & 46 & 48 & 47 & 45.5 \\
\hline & 5 & 42 & 47 & 48 & 48 & 46.25 \\
\hline & 6 & 40 & 45 & 46 & 46 & 44.25 \\
\hline \multirow{6}{*}{900} & 1 & 33 & 39 & 37 & 36 & 36.25 \\
\hline & 2 & 37 & 42 & 41 & 43 & 40.75 \\
\hline & 3 & 39 & 40 & 40 & 41 & 40 \\
\hline & 4 & 38 & 45 & 47 & 47 & 44.25 \\
\hline & 5 & 40 & 46 & 47 & 46 & 44.75 \\
\hline & 6 & 38 & 43 & 44 & 45 & 42.5 \\
\hline \multirow{6}{*}{1000} & 1 & 34 & 40 & 40 & 37 & 37.75 \\
\hline & 2 & 35 & 41 & 42 & 41 & 39.75 \\
\hline & 3 & 37 & 39 & 41 & 40 & 39.25 \\
\hline & 4 & 41 & 47 & 46 & 46 & 45 \\
\hline & 5 & 41 & 47 & 48 & 47 & 45.75 \\
\hline & 6 & 39 & 44 & 45 & 43 & 42.75 \\
\hline
\end{tabular}

The studies showed that the soaking time of 5 hours was optimal to obtain the required hardness of the deposited coating (Fig. 1), and in the temperature range from $800^{\circ} \mathrm{C}$ to $1,000^{\circ} \mathrm{C}$ in the deposited metal there were practically no changes in hardness (Fig. 2). Thus, to increase the 
hardness of the metal deposited with the CSR-04CR27NI7MO3CU2T cast rods of the coatings, it is possible to recommend the following heat treatment modes -

1. Heating up to $800{ }^{\circ} \mathrm{C}$ with a furnace.

2. 5 hours of soaking time.

3. Cooling by ambient air.

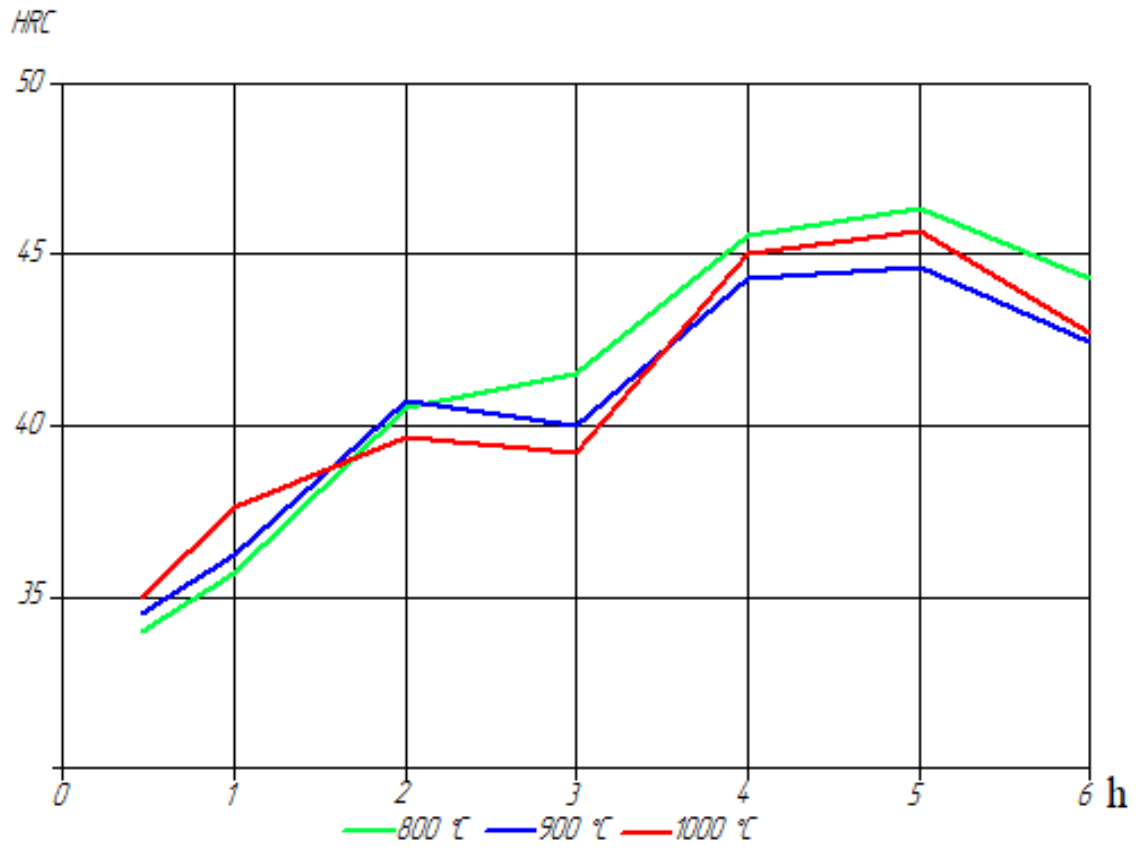

Fig. 1. Influence of Soaking Time on Hardness of Coating (Average Values) Obtained by Surfacing with CSR-04CR27NI7MO3CU2T Cast Bars in Temperature Range of 800-1,000 ${ }^{\circ} \mathrm{C}$

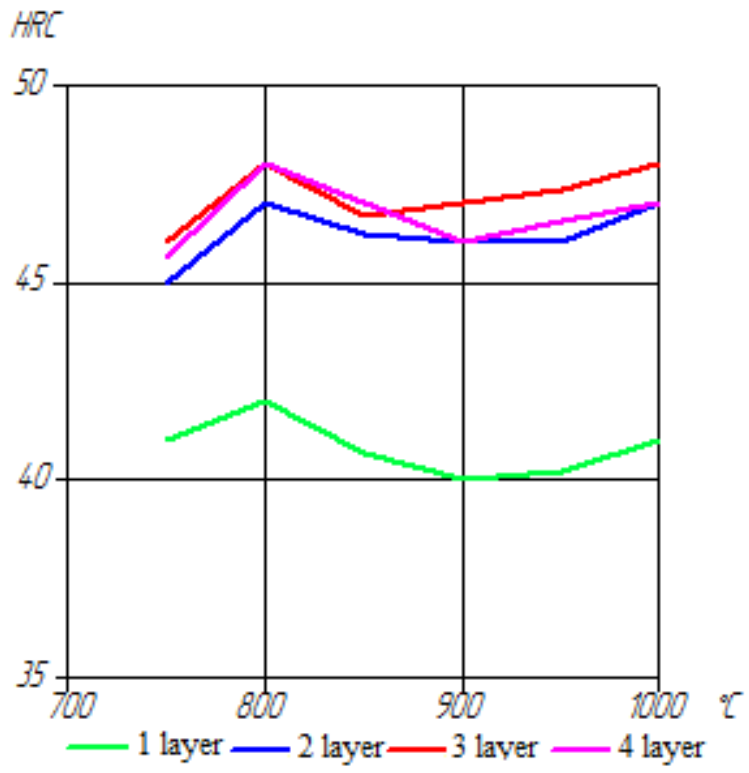

Fig. 2. Influence of Heat Treatment Temperature (with Soaking Time of 5 Hours) on Hardness of Coating Obtained by Surfacing with CSR-04CR27NI7MO3CU2T Cast Rods 
For a complete representation of the distribution of hardness over the cross-section of coatings after surfacing and heat treatment $\left(800^{\circ} \mathrm{C}-5\right.$ hours $)$, the total hardness of the metal was researched in accordance with the method of Rockwell. The results are shown in Fig. 3.

It can be seen that after heat treatment, the hardness is uniformly distributed over the deposited metal cross-section in the range of 45-48 HRC. This hardness of the coating ensures high wear resistance of the deposited coatings.

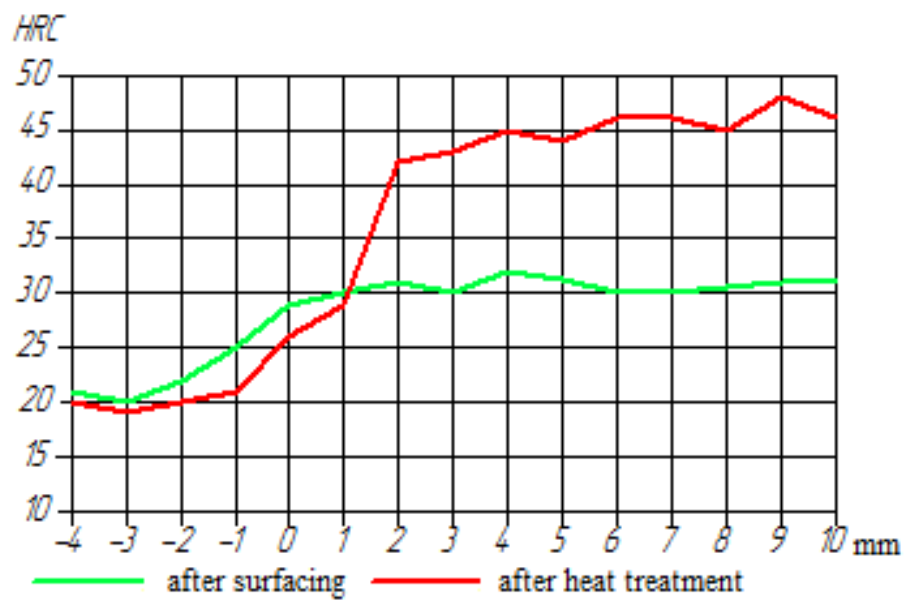

Fig. 3. Distribution of Metal Hardness over Cross-Section of Coating Obtained by Surfacing with CSR-04CR27NI7MO3CU2T Cast Rods

The results of measuring the microhardness over the cross section of the deposited metal after heat treatment are shown in Fig. 4. There, the distribution of microhardness in the metal of coatings after the procedure of surfacing is also presented.

Analyzing the results obtained, it is possible to note that the microhardness in the metal after surfacing varies within $315-404 \mathrm{HV}$. After heat treatment $\left(800^{\circ} \mathrm{C}-5\right.$ hours $)$, the microhardness significantly increases to the values from $415 \mathrm{HV}$ to $570 \mathrm{HV}$.

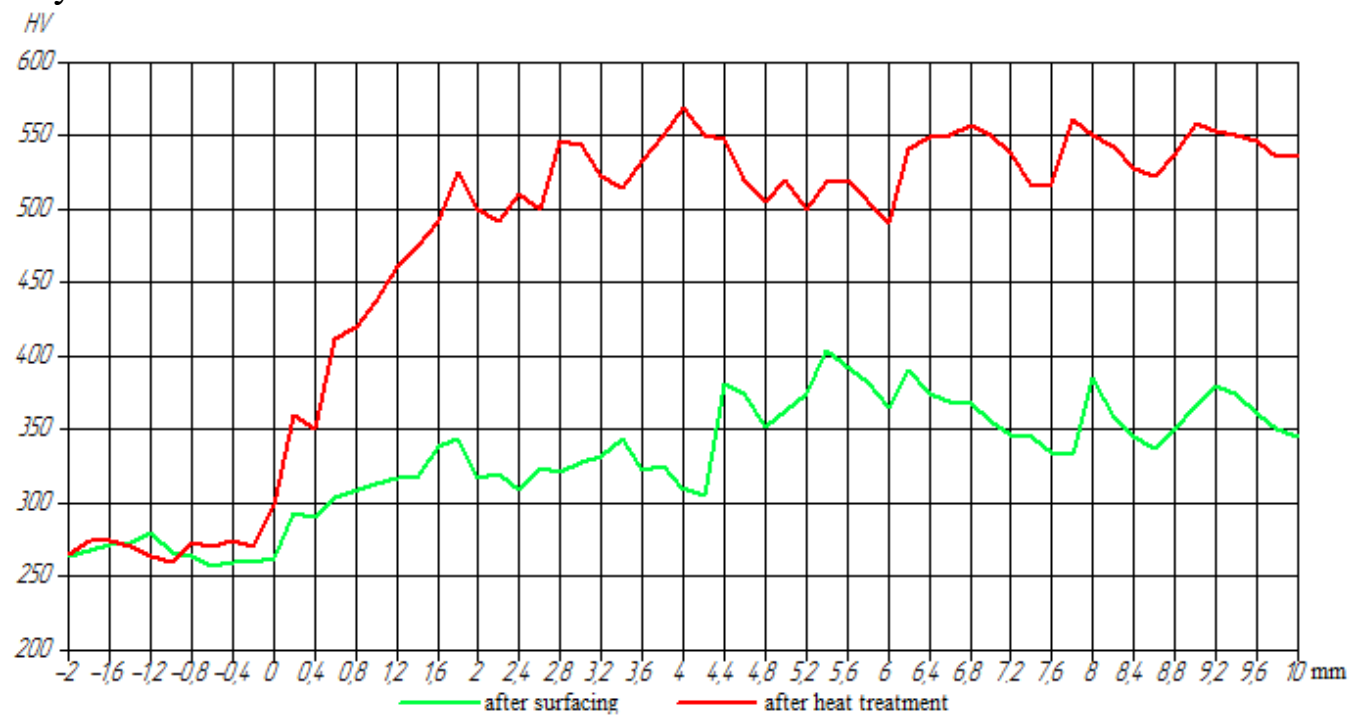

Fig. 4. Distribution of Microhardness over Cross-Section of Coating Obtained by Surfacing with CSR-04CR27NI7MO3CU2T Cast Rods 
The microstructure of the metal deposited with CSR-04CR27NI7MO3CU2T cast rods, is represented by the mixture of ferrite $(\alpha-\mathrm{Fe})$ and austenite $(\gamma-\mathrm{Fe})$ (Fig. 5). The accumulation of strengthening phases is observed along the grain boundaries. This mixed structure has a hardness of 29-32 HRC.

The places of measurement and the values of the microhardness of the structural components of the metal after surfacing are shown in Fig. 6 and in Table 2.

As we can see, the microhardness of the matrix varies from 315 to $355 \mathrm{HV}$, and that of the hardening phases - from 364 to $451 \mathrm{HV}$.
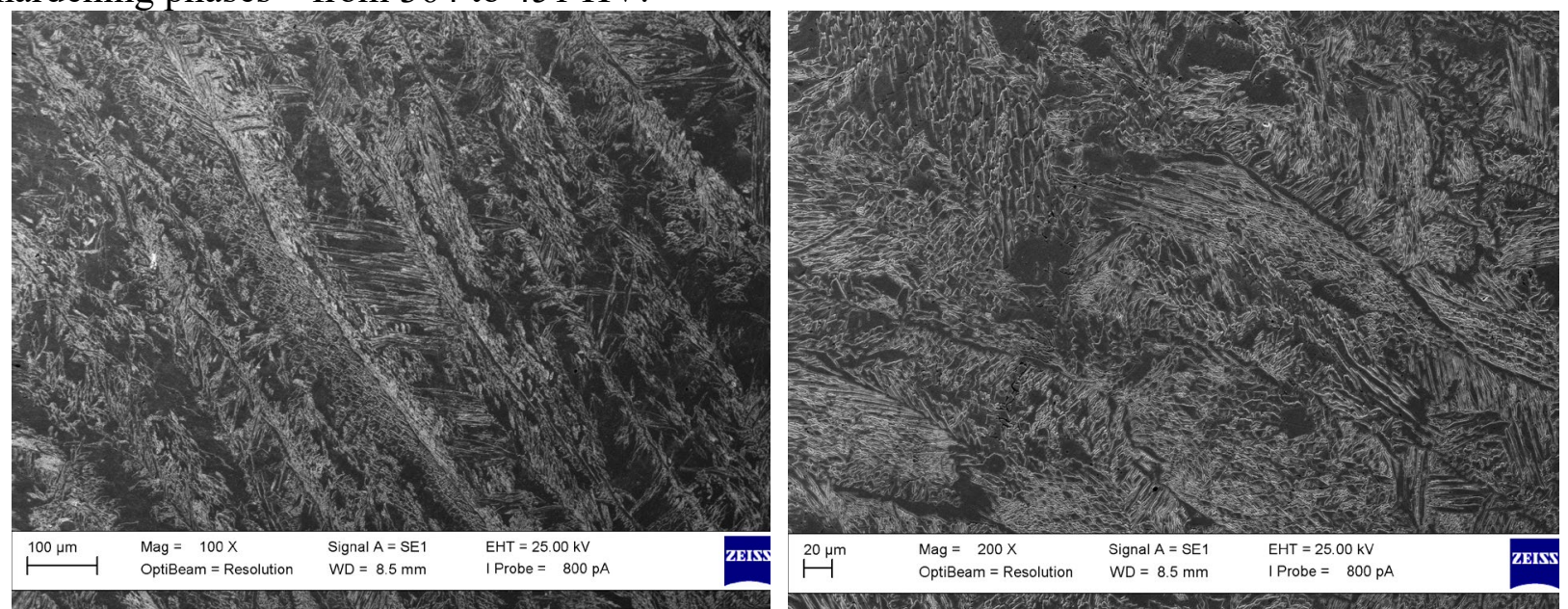

Fig. 5. Microstructure of Metal Deposited with CSR-04CR27NI7MO3CU2T Cast Rods

Table 2. Microhardness HV 0,01 of Structural Components of Metal Deposited with CSR04CR27NI7MO3CU2T Cast Rods

\begin{tabular}{|c|c|c|c|c|c|c|c|c|c|c|c|c|}
\hline Puncture No. & $\mathbf{1}$ & $\mathbf{2}$ & $\mathbf{3}$ & $\mathbf{4}$ & $\mathbf{5}$ & $\mathbf{6}$ & $\mathbf{7}$ & $\mathbf{8}$ & $\mathbf{9}$ & $\mathbf{1 0}$ & $\mathbf{1 1}$ & $\mathbf{1 2}$ \\
\hline $\begin{array}{c}\text { Microhardness } \\
\text { value, HV }\end{array}$ & 315 & 404 & 451 & 439 & 421 & 338 & 364 & 445 & 355 & 346 & 322 & 383 \\
\hline
\end{tabular}

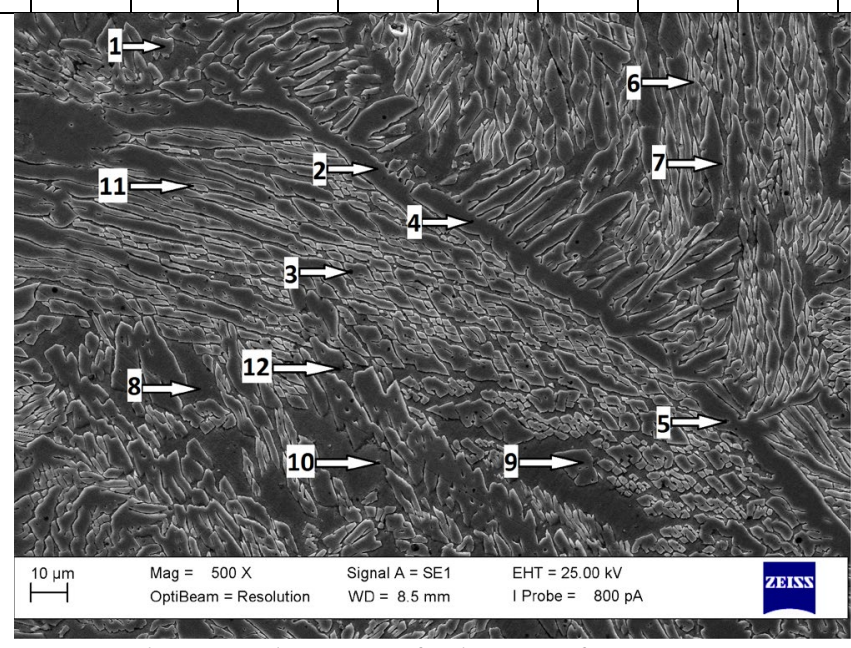

Fig. 6. Microstructure with Distribution of Places of Measurement of Microhardness of Structural Components of Metal of Coating Deposited with CSR-04CR27NI7MO3CU2T Cast Rods

Heat treatment of the studied coating at the temperature of $800^{\circ} \mathrm{C}$ and soaking for 5 hours led to changes in the microstructure of the deposited metal. As a result of heat treatment in the 
deposited metal, the structural components decomposition occurred (Fig. 7), i. e., all ferrite ( $\alpha-\mathrm{Fe})$ passed into the $\sigma$-phase $(\mathrm{FeCr})$, which caused the hardness increase from $31 \mathrm{HRC}$ to $48 \mathrm{HRC}$.

The microhardness of the structural components of the deposited metal after heat treatment of the coating under research increased significantly (Fig. 8, Table 3).

As we can see, the microhardness of the deposited metal matrix after heat treatment increased significantly - from $415 \mathrm{HV}$ to $566 \mathrm{HV}$, and the microhardness of the strengthening phases changed from $539 \mathrm{HV}$ to $786 \mathrm{HV}$. Such structure changes caused a significant increase in hardness.
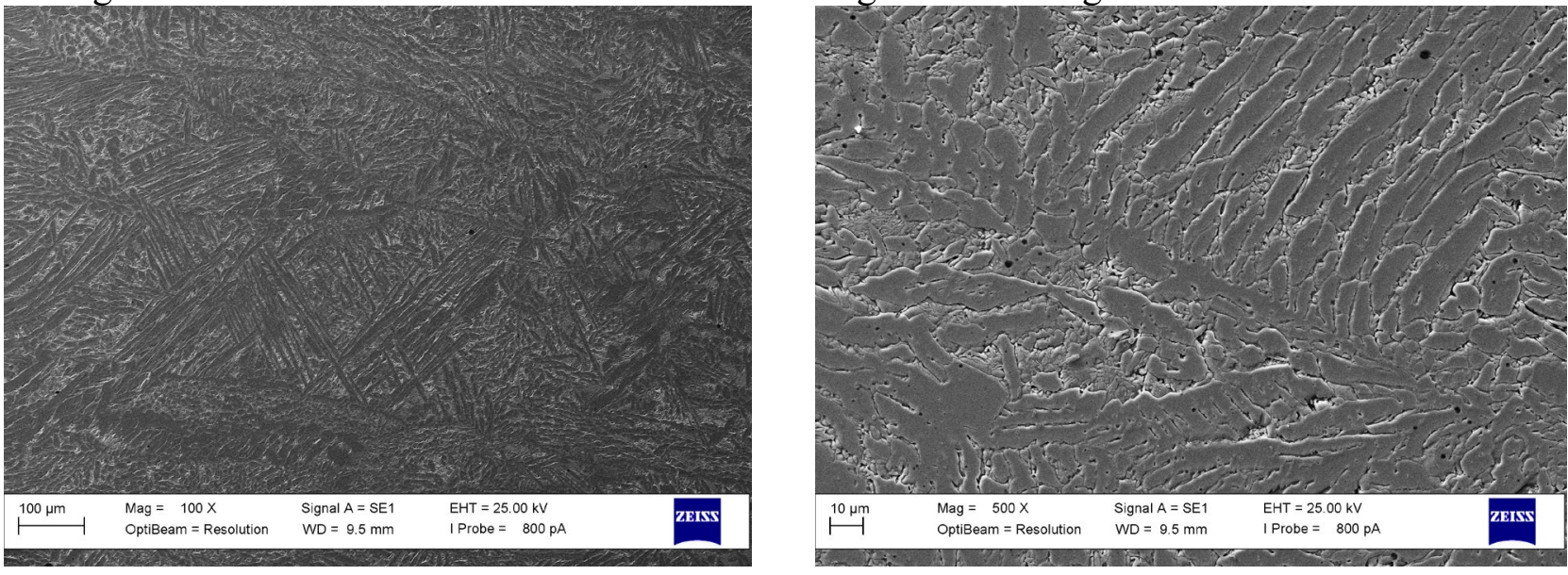

Fig. 7. Microstructure of Metal of Coating Deposited with CSR-04CR27NI7MO3CU2T Cast Rods after Heat Treatment at $800^{\circ} \mathrm{C}$ during 5 Hours.

Table 3. Microhardness HV 0,01 of Structural Components of Metal Deposited with CSR04CR27NI7MO3CU2T Cast Rods after Heat Treatment

\begin{tabular}{|c|c|c|c|c|c|c|c|c|c|c|c|c|}
\hline $\begin{array}{c}\text { Puncture No. } \\
\begin{array}{c}\text { Microhardness } \\
\text { value, HV }\end{array}\end{array}$ & $\mathbf{1}$ & $\mathbf{2}$ & $\mathbf{3}$ & $\mathbf{4}$ & $\mathbf{5}$ & $\mathbf{6}$ & $\mathbf{7}$ & $\mathbf{8}$ & $\mathbf{9}$ & $\mathbf{1 0}$ & $\mathbf{1 1}$ & $\mathbf{1 2}$ \\
\hline
\end{tabular}

Fig. 8. Microstructure with Distribution of Places of Measurement of Microhardness of Structural Components of Metal of Coating Deposited with CSR-04CR27NI7MO3CU2T Cast Rods after Heat Treatment 
To redefine the chemical composition of structural components in the deposited metal after heat treatment, studies were carried out with the help of a scanning electron microscope [3].
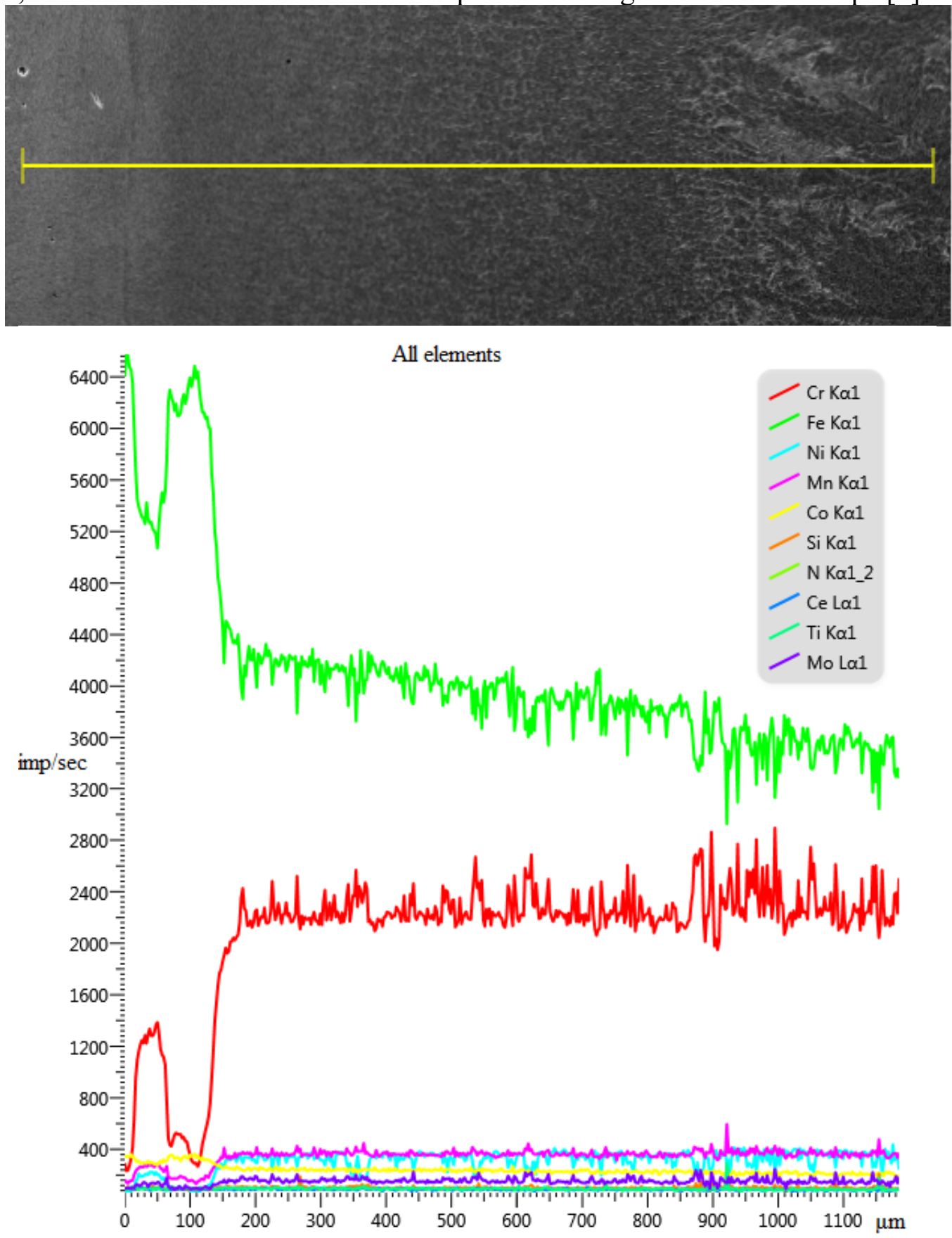

Fig. 9. Results of Scanning Metal Structure over Cross-Section of Coating Deposited with CSR04CR27NI7MO3CU2T Cast Rods after Heat Treatment 

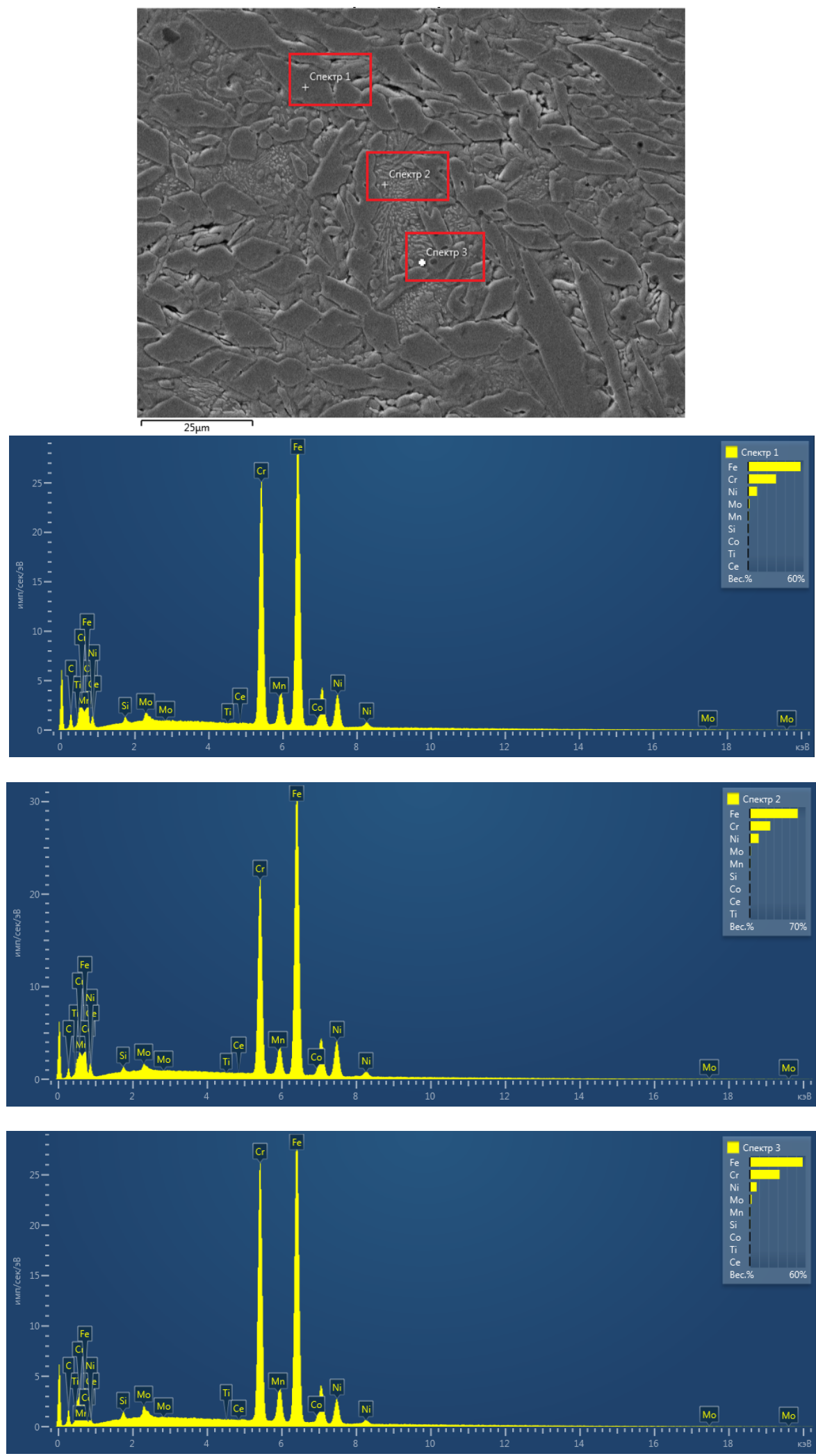

Fig. 10. Results of Spectra of Local Spot Analysis of Structural Components of Metal of Coating Deposited with CSR-04CR27NI7MO3CU2T Cast Rods after Heat Treatment at $800^{\circ} \mathrm{C}$ during 5 Hours. 
Table 4. Chemical Composition of Areas of Coating Deposited with CSR-04CR27NI7MO3CU2T Cast Rods, wt. \%

\begin{tabular}{|c|c|c|c|c|c|c|c|c|c|c|c|c|}
\hline Spectrum & $\mathbf{C}$ & $\mathbf{S i}$ & $\mathbf{M n}$ & $\mathbf{C r}$ & $\mathbf{N i}$ & $\mathbf{M o}$ & $\mathbf{N}$ & $\mathbf{C o}$ & $\mathbf{T i}$ & $\mathbf{C e}$ & $\mathbf{C u}$ & $\mathbf{F e}$ \\
\hline 1 & 0.03 & 0.53 & 0.9 & 27.29 & 8.72 & 2.5 & 0.05 & 0.18 & 0.31 & 0.03 & 2.15 & 57.31 \\
\hline 2 & 0.04 & 0.52 & 0.86 & 25.71 & 7.24 & 3.16 & 0.11 & 0.19 & 0.48 & 0.08 & 2.1 & 59.51 \\
\hline 3 & 0.05 & 0.69 & 0.82 & 29.18 & 7.33 & 3.44 & 0.09 & 0.2 & 0.46 & 0.05 & 1.73 & 55.96 \\
\hline
\end{tabular}

Based on the data obtained, reflecting the quantitative distribution of elements along the segment in the form of concentration spectrograms over the cross-section of the deposited coating, starting with the base metal (Fig. 9) and spectra of local spot analysis (Fig. 10, Table 4), it follows that the strengthening of the metal deposited with CSR-04CR27NI7MO3CU2T cast rods is mainly conditioned by the presence of the $\sigma$-phase precipitated along the grain boundaries of the intermetallic compound (FeCr), as well as chromium carbides $\left(\mathrm{Cr}_{3} \mathrm{C}_{2}\right)[4,5]$ and titanium carbides (TiC).

\section{Conclusions}

1. To increase the hardness of the deposited metal, it is advisable to carry out heat treatment at a temperature of $800^{\circ} \mathrm{C}$ and soaking for 5 hours. The hardness of this metal reaches $45-48 \mathrm{HRC}$, which ensures high wear resistance of the deposited coatings. This is explained by an increase in the microhardness of structural components due to the formation of an austenite structure strengthened by precipitates of the $\sigma$-phase $(\mathrm{FeCr})$, chromium carbides $\left(\mathrm{Cr}_{3} \mathrm{C}_{2}\right)$, and titanium carbides (TiC).

2. The proposed mode of heat treatment can be used in the technology of wear-resistant surfacing of parts of chemical equipment operating under conditions of urea melt $\left(\mathrm{H}_{2} \mathrm{NCONH}_{2}\right)$, at pressures up to $20 \mathrm{MPa}$ and temperature of $200^{\circ} \mathrm{C}$, gaseous and liquid ammonia, ammonium nitrate.

\section{Acknowledgments}

The research was carried out with the financial support of the Kuban Science Foundation in the framework of the Scientific Project No. МФИ-20.1/26².

\section{References}

[1] ST CKBA 053-2008. Armatura truboprovodnaya. Naplavka i kontrol kachestva naplavlennykh poverkhnostey. Tekhnicheskiye trebovaniya. [Pipe Fittings. Surfacing and Quality Control of Welded Surfaces. Technical Requirements].

[2] COMPOSITION FOR PARTS SURFACING. Nazarko A.S., Plomodyalo R.L., Demonov M.S. Invention Patent RU 2711488 C1, 17.01.2020. Application No. 2018147605 dated 28.12.2018.

[3] Yeremin Ye.N., Losev A.S., Borodikhin S.A., Filippov Yu.O., Ponomarev I.A., Matalasova A.Ye. Effect of Heat Treatment on Structure and Properties of Coatings Based on Martensitic Chromium Steel Obtained by Surfacing with Flux-Cored Wire // Omsk Scientific Bulletin. Ser. Aircraft Missile and Power Engineering. 2017. Vol. 1, No. 2. Pp. 41-48.

[4] Bhambri S. K. Intergranular fracture in $13 \mathrm{wt} \%$ chromium martensitic stainless steel // Journal of Material Science. 1986. Vol. 21, Issue 5. Pp. 1741-1746.

[5] Schäfer L. Influence of delta ferrite and dendritic carbides on the impact and tensile properties of a martensitic chromium steel // Journal of Nuclear Materials. 1998. Vol. 258. Pp. $1336-1339$. 